\title{
Re-evaluation of the Mesozoic mantis shrimp Ursquilla yehoachi based on new material and the virtual peel technique
}

\author{
Carolin Haug, Verena Kutschera, Shane T. Ahyong, Francisco J. Vega, \\ Andreas Maas, Dieter Waloszek, and Joachim T. Haug
}

\begin{abstract}
We re-evaluate the Mesozoic mantis shrimp Ursquilla yehoachi, based on the original four specimens and a new exquisitely preserved one. All specimens were documented by application of a new technique, which is introduced here and termed the virtual peel technique. This technique includes two steps: 1) Documentation of lowrelief fossils including their 3D information with the aid of a standard flat-bed scanner. 2) Virtual inversion of the negative relief of fossils; the resulting positive relief facilitates a better understanding of the fossil. Unlike the previously known specimens, the new specimen of $U$. yehoachi preserved most details of the uropod including the exopod, an important feature in stomatopod phylogeny. Remarkably, this exopod bears striking similarities to that of modern stomatopods in being bipartite and having a paddleshaped distal part, supporting earlier assumptions about the systematic position of $U$. yehoachi within Squilloidea. Observable morphological differences among the available material of $U$. yehoachi can now be identified as ontogenetic variation. The telson, for example, attains a proportionally broader shape with increasing size, a result of allometric growth.
\end{abstract}

Carolin Haug. Department of Cytology and Evolutionary Biology, Zoological Institute and Museum, University of Greifswald, Soldmannstrasse 23, 17487 Greifswald, Germany carolin.haug@palaeo-evodevo.info

Verena Kutschera. Biosystematic Documentation, University of Ulm, Helmholtzstrasse 20, 89081 Ulm, Germany verena.kutschera@uni-ulm.de

Shane T. Ahyong. Australian Museum, 6 College Street, Sydney, NSW 2010, Australia

Shane.Ahyong@austmus.gov.au

Francisco J. Vega. Instituto de Geología, UNAM, Ciudad Universitaria, Coyoacán, México DF 04510, Mexico vegver@unam.mx

Andreas Maas. Biosystematic Documentation, University of Ulm, Helmholtzstrasse 20, $89081 \mathrm{UIm}$, Germany andreas.maas@uni-ulm.de

Dieter Waloszek. Biosystematic Documentation, University of Ulm, Helmholtzstrasse 20, 89081 Ulm, Germany dieter.waloszek@uni-ulm.de 
Joachim T. Haug. Department of Cytology and Evolutionary Biology, Zoological Institute and Museum, University of Greifswald, Soldmannstrasse 23, 17487 Greifswald, Germany joachim.haug@palaeo-evodevo.info

Keywords: virtual peel technique; three dimensional documentation; Stomatopoda; Cretaceous; tail fan

\section{INTRODUCTION}

The holotype specimen of Ursquilla yehoachi (Remy and Avnimelech, 1955) is from the Upper Cretaceous of Israel and was originally interpreted as the head shield of the eryonid decapod crustacean Eryon yehoachi (Remy and Avnimelech, 1955). Fourteen years later, Glaessner (1969) recognized this interpretation as being erroneous and identified the supposed head shield as the telson or tail end of a mantis shrimp (squillid malacostracan crustacean). This was an important discovery because mantis shrimps, so far, do not have an extensive fossil record as, for example, decapods (recent lists of fossil stomatopods in Schram, 2010; see also Ahyong et al., 2007; Haug, J.T. et al., 2008, 2010; Haug, C. et al., 2009a; a single, generally unrecognized Silurian specimen with supposed stomatopod affinities was reported by Wetzel, 1973).

Hof (1998a) supported and formalized the interpretation of Glaessner (1969) in transferring "Eryon" yehoachi to the newly erected taxon Ursquilla Hof, 1998. Furthermore, based on additional material, Hof (1998a) suggested that $U$. yehoachi should be best interpreted as an in-group representative of Stomatopoda, due to its "modern" morphology, therefore should be assigned to Squilloidea Latreille, 1802. However, Hof (1998a) also mentioned the possibility that the exopod of the uropod of Ursquilla yehoachi might have been undivided. An undivided uropodal exopod is, for example, developed in Mesozoic non-verunipeltatan mantis shrimps, whereas a bipartite uropodal exopod is one of the autapomorphies of the stomatopod in-group Verunipeltata, which represents the group that includes all living taxa (Haug, J.T. et al., 2010). Accordingly, the uropodal exopod morphology of $U$. yehoachi is of significance for its systematic positioning and the understanding of the evolution of mantis shrimps. An undivided uropodal exopod could indicate that $U$. yehoachi had branched off from the evolutionary lineage towards Verunipeltata rather than being part of the in-group. Alternatively, if the uropodal exopods were bipartite, U. yehoachi was a representative of Verunipel- tata following Hof (1998a) (so in a way contrasting his mentioning) and Ahyong (2005). In this case, as Hof $(1998 a, b)$ pointed out, the occurrence of $U$. yehoachi would also be an indication that all major groups of modern mantis shrimps were already present in the Cretaceous.

Fortunately, more recently a new specimen of Ursquilla yehoachi became available in addition to the four specimens already known, encouraging a re-study of this species. With newly developed techniques such as composite fluorescence imaging and the here proposed virtual peel technique this specimen was documented to a high degree of detail. The data and images resulting from these methods were then compared to results based on other relatively new, but already well-established methods of documentation, such as micro-computed tomography (micro-CT) and surface scanning. Additionally, all of the earlier known specimens of $U$. yehoachi were re-documented for a thorough comparison with the new specimen. Based on this, we re-evaluated $U$. yehoachi and its impact on the understanding of mantis shrimp evolution.

\section{MATERIAL AND METHODS}

\section{Material}

The complete known material of Ursquilla yehoachi was documented and investigated for this study. This includes the material described by Hof (1998a; specimens MNHN R. 62691 (holotype) and a resin cast of it (BMNH I 15472), GSI M-8113, BMNH I 7316, all specimens are from the Upper Cretaceous; see Hof 1998a for details on these specimens) and one new specimen, which was the basis for this study. All specimens are fragments and represent only the isolated caudal body ends of $U$. yehoachi. Only the inner side of the dorsal body wall is preserved in all specimens. The new specimen was collected by Stan Natkaniec, Düsseldorf, during a private trip to the Negev Desert, Israel. The specimen was subsequently donated to the Staatliches Museum für Naturkunde Stuttgart, Germany, and is now part of its collection under 
specimen number SMNS 67703. The find was identified as a specimen of $U$. yehoachi by Günter Schweigert, Stuttgart. The posterior part of an airdried specimen of Squilla mantis (Linnaeus, 1758) was also studied for comparison.

\section{Methods}

Hof (1998a) studied the four specimens known at that time directly, but also made investigations on peels made from these. These peels are of special interest because on the fossils the inner side of the dorsal cuticle is exposed. The peel, therefore, gives a better impression on the real morphology during life by resembling more closely a view of the dorsal side (though it is still the inner surface of the procuticula and not the outer surface of the top layer, the epicuticula, which provides the fine details such as denticles and delicate folds and pores). Yet, producing peels is not unproblematic and may actually damage a fossil. As the newly discovered specimen was at first part of a private collection, we aimed at avoiding any possible damage and searched for suitable methods to invert the topology of the fossil with as little physical interaction with its surface as possible. Different methods were, therefore, tested on the newly discovered specimen.

Micro-CT scan. The scan was performed using an experimental computer tomograph, a micro-CT called "Paula", at the company Wenzel Knotenpunkt, Balingen, Germany, which develops Reverse Engineering Technology software especially for three dimensional computer graphics imaging in cooperation with the company Descam, Oberhaching. The resulting data were exported as a surface model. This was imported into the freely available 3D software Blender, in which a stereo image was rendered.

Surface scan and physical peel. A surface scan of the specimen was recorded with a Digiscan Girrbach at the Department of Dentistry, Clinic for Dental Prosthetics, University of Ulm. However, this method did not yield sufficiently detailed results, as the most strongly depressed parts of the fossil could not be recorded, and the final surface model contained voids. To overcome this problem, a physical peel was made with dental casting compound, which became possible as the specimen had become part of a museum collection. The peel was then scanned with the same machine. The resulting images were satisfying as the peel was the positive counterpart of the fossil specimen with no depressed parts, leading to a surface model without holes.
Virtual peel. Another method applied is termed "virtual peel" technique by us. The basic idea of this partly new method follows Schubert (2000) and uses a standard flat-bed scanner for documenting objects. This method has successfully been applied to flat fossils with only low relief, such as those from the Hunsrück Slate (Haas et al., 2003). By following the technique of Schubert (2000) it is also possible to produce three-dimensional images of an object. For this purpose, the specimens of $U$. yehoachi were placed on the glass plate of the flat-bed scanner, the plate protected by an overhead transparency. After the specimen is scanned in the first position, the overhead transparency with the specimen on it is carefully pulled sideward about $8 \mathrm{~cm}$ avoiding any rotation. Because of the special optical properties of flat-bed scanners these different scanning positions result in different perspectives of the created single images, i.e., right and left images appear as if made at different angles of view (see Schubert, 2000 for theoretical details). The two images can then be used to produce a stereo-anaglyph image (e.g., in Adobe Photoshop, being positioned on two different layers, changed to colour mode, reduced to red and green channel and the overlaying image layer reduced in opacity by about 50 percent). This was done for the specimen of Squilla mantis and the resin cast of the holotype (BMNH I 15472).

As the fossils provide a view on the internal surface of their dorsal side, inverting the topology reveals a good proxy of the external appearance of the dorsal surface (although the original dorsal surface remains unknown). For this purpose, usually physical peels are used. Since physical peels may damage the specimen, we further executed the resulting two images in the following way. We changed the positions of the two single images of the stereo image, i.e., what is usually the left image was treated as the right image and vice versa. This leads to a depth inversion of the stereo image. As this procedure has a comparable effect to producing a physical peel, we term our approach "virtual peel", i.e., the combined method of using a flat-bed scanner to produce a stereo image and invert the depth of this resulting image.

One specimen could not be documented in this way. The matrix of this specimen from the collection of the Geological Survey of Israel, Jerusalem, (GSI M-8113) protrudes far out from the surface, so preventing from being placed on the scanner. Therefore, we produced the two half images with a Canon EOS 450D camera and 
treated them as described above to invert the depth of the stereo image.

Composite fluorescence imaging. For resolving small details of the newly discovered specimen, parts were documented using composite fluorescence microscopy (for details see, e.g., Haug, J.T. et al., 2008; Kerp and Bomfleur, 2011). This was possible because the specimen autofluoresces when exposed to green light (546 nm). Image stacks were recorded using a Zeiss Axioskop 2 equipped with an AxioCam at the Institute of Anatomy and Cell Biology, University of Ulm. Stacks were fused using the "do stack" macro of the freely available software CombineZM. The resulting fused images were stitched in Adobe Photoshop CS3, either with the "Photomerge" function or by hand, orienting along apparent landmarks.

Drawings. Scientific pencil drawings were made for Ursquilla yehoachi based on the new images of all specimens and on the additional studies of SMNS 67703 under a dissection microscope (Leica MS 5). The drawings of the uropodal exopods of Sculda pennata Münster, 1840 and Pseudosculda laevis (Schlüter, 1874) were based on previous studies of these species (see Haug, C. et al., 2009b; Haug, J.T. et al., 2010). The drawing of the exopod of the uropod of a presumed pseudosculdid from the Cretaceous of Mexico was based on a photograph by Vega et al. (2007, figure 5.6). The drawing of the uropodal exopod of Squilla mantis was produced from a specimen examined with a Leica MS 5 dissection microscope. The drawings were scanned with a CanoScan $8800 \mathrm{~F}$ at 1200 ppi and reworked in Adobe Photoshop CS 3.

\section{RESULTS}

\section{Systematic Palaeontology}

Hoplocarida Calman, 1904

Stomatopoda Latreille, 1816

Unipeltata Latreille, 1825 sensu lato

Unipeltata Latreille, 1825 sensu stricto

Verunipeltata Haug, J.T. et al., 2010

Squilloidea Latreille, 1802

Squillidae Latreille, 1802

(for synonymy of Squillidae see Ahyong, 2005 and

Schram, 2010)

Ursquilla Hof, 1998a

Ursquilla Hof, 1998a: 258. - Ahyong and Harling, 2000: 625. - Schram and Müller, 2004: 203. - Ahyong, 2005: 189, 191, 193, 197, 200, 202; figure 4; apps. 1, 2. - Ahyong et al., 2008: 61. - Schweitzer and Feldmann, 2010: 412.
Type species: Eryon yehoachi Remy and Avnimelech, 1955, by original designation.

Ursquilla yehoachi (Remy and Avnimelech, 1955)

Eryon yehoachi - Remy and Avnimelech, 1955: 311, 313; pl. 14a1 (MNHN R. 62691).

"Eryon" yehoachi - Glaessner, 1969: R470 [reinterpreted as a "Squilla-like stomatopod telson"].

Ursquilla yehoachi - Hof, 1998a: 258; figures 2A (MNHN R. 62691), 2C (GSI M-8113), 3A (BMNH I 7316). - Schram and Müller, 2004: 203. - Ahyong, 2005: 189, 200, tab. 2, app. 1. - Ahyong et al., 2007: 11, 12. - Vega et al., 2007: 407. — De Angeli and Garassino, 2008: 172. - Schweitzer and Feldmann, 2010: 412, figure 3 (MNHN R. 62691).

\section{Details on the new specimen SMNS 67703 (Figures 1, 2)}

Remarks: Hof (1998a) described the morphology of the tergite of the sixth pleomere and the telson in minute detail. We cannot add any significant new details to this aspect of the description (compare the new specimen in Figures 1 and 2 with the already known specimens in Figure 3 ). Therefore, we do not describe these structures apart from noting that the structures on the lateral margins of the telson, which Hof (1998a) referred to as 'lateral folds', represent the prelateral lobes, a derived squilloid feature (Ahyong and Harling, 2000).

Tergites of pleomeres 4 and 5 are less well preserved than pleomere 6 but appear to be generally similar, apart from more pronounced submedian, intermediate and lateral carinae of the tergite of pleomere 6 (Figure 1). The intermediate and lateral carinae of the tergite of pleomere 5 are preserved on the left side of specimen SMNS 67703 (Figure 1); submedian carinae may also be present, but these are not clearly preserved. The tergite of the fourth pleomere is more poorly preserved than that of the fifth, especially the lateral aspects.

The following new details are recognized on the uropod of SMNS 67703 (Figures 1, 2.1-3): The supposed endopod is better visible on the left side, as it is almost completely concealed by the telson on the right side. However, also the endopod of the left uropod is incompletely preserved, and its distal part is missing as it extended beyond the stone (Figure 1). It is in general of elongate oval shape, possibly with a median keel (Figure 2.1), but further details are not detectable. Possibly, also the basipodal spine is preserved on the left uropod, but 


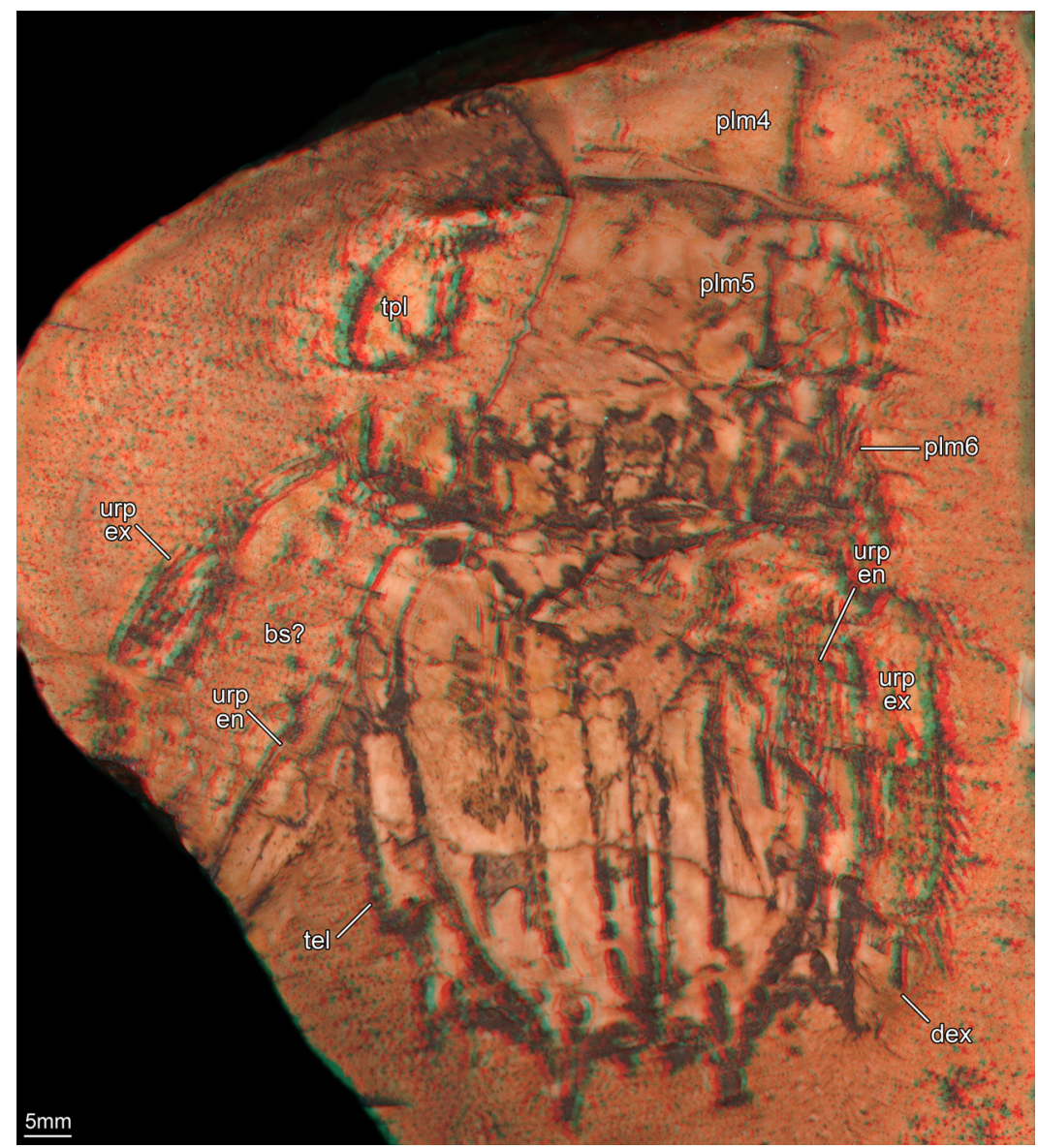

FIGURE 1. A virtual peel, i.e., an inverted red-cyan stereo image, of the new specimen of Ursquilla yehoachi (Remy and Avnimelech, 1955), SMNS 67703. The specimen represents the posterior part of the body, including the telson and the three posterior pleomeres. Use red-cyan stereo glasses to view. Abbreviations: bs? = possible basipodal spine; dex = distal part of exopod; plm = pleomere; tel = telson; tpl = tergopleura; urp en = uropodal endopod; urp ex = uropodal exopod.

not well enough to study any details. The uropodal exopod is bipartite with a sub-rectangular, but slightly C-shaped proximal element, which articulates against the smaller distal paddle-shaped element. The proximal area of the proximal portion and, hence, the articulation against the basipod, is unknown due to preservation; the full length of this element can only be estimated as being about 35 $\mathrm{mm}$ long and $11 \mathrm{~mm}$ wide. Possibly up to 11 articulated spines arise along the lateral margin of the proximal element (Figure 2.2-3), pointing posterolaterally. The most proximal one inserts more laterally. The spines increase in length from proximal to distal, with the most proximal spine being less than $2 \mathrm{~mm}$ long and the second most distal spine about $7 \mathrm{~mm}$ in length (the most distal spine appears to be broken off). The distal paddle-shaped portion of the exopod is only faintly preserved, its dimensions can only be estimated as being about $12 \mathrm{~mm}$ long and $6 \mathrm{~mm}$ wide at most. Along the rim are faint indications of fine spines or setae.

\section{DISCUSSION}

\section{Evaluation of the Methods Applied}

The investigations of the specimens of Ursquilla yehoachi have provided certain challenges. The fossils possess a low relief, i.e., they are not completely flattened. Such a relief may cause artefacts when directed light is applied (Hörnschemeyer and Handschuh, 2009). By this, structures appear to be present, but are in fact not, or truly present structures may not be visible under a certain angle of light. Therefore, we preferred neutral lighting to document such low-relief fossils in order to enhance the comparability among several specimens. A convenient solution for such fossils, as investigated in this study, is the use of a 

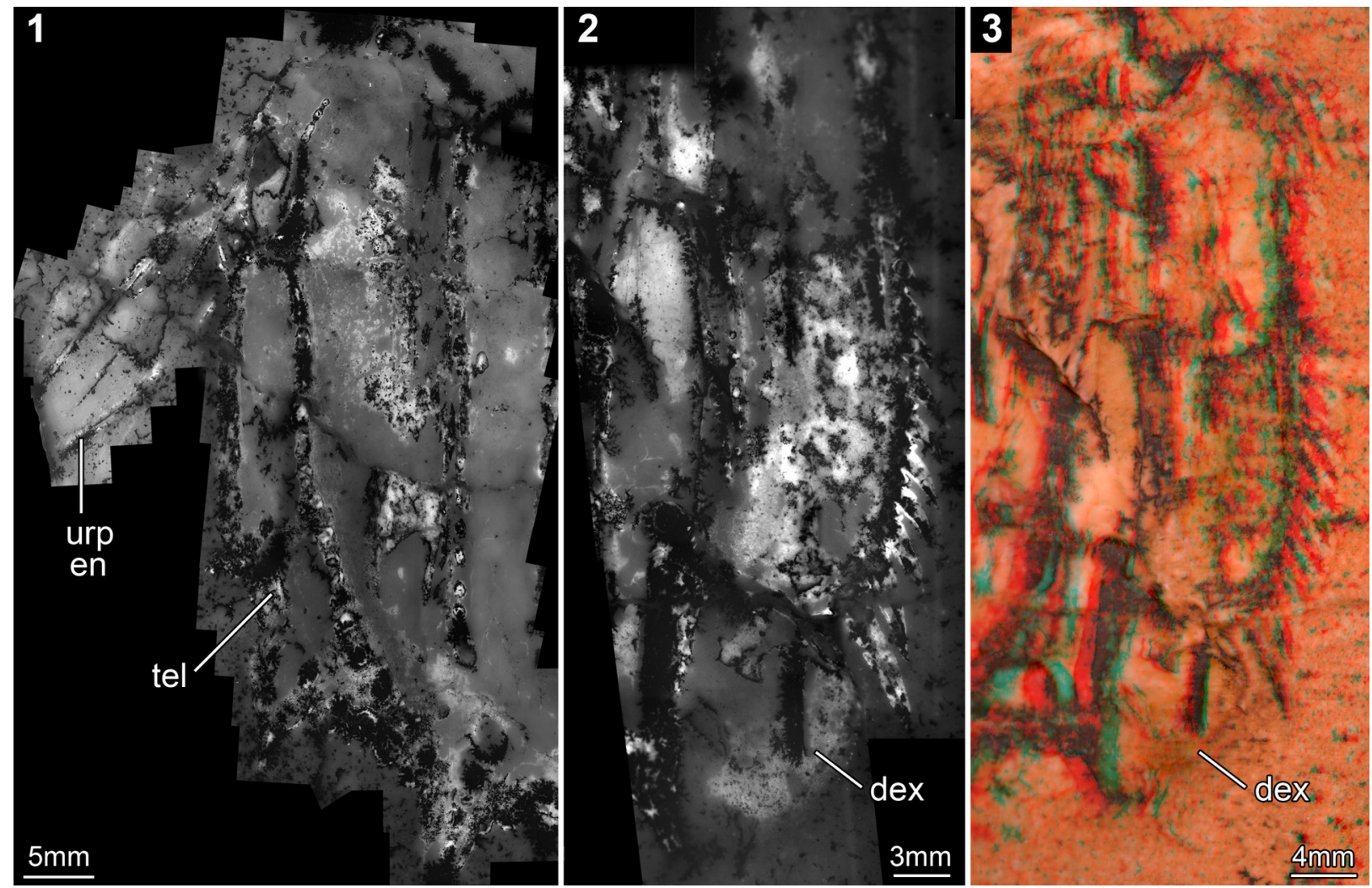

FIGURE 2. Details of the new specimen of Ursquilla yehoachi (Remy and Avnimelech, 1955), SMNS 67703. 2.1-2. Composite autofluorescence images (e.g., Haug, J.T. et al., 2008). Note that under fluorescence settings there are details visible, e.g., exact shape of the spines on the uropodal exopod, which are not visible under white-light conditions (see Figures 1, 2.3). 2.1. Part of the possible endopod of the left uropod and left part of the telson. 2.2. Right uropod with the articulated distal part of the exopod. 2.3. Virtual peel of the same area as in Figure 2.2. Use red-cyan stereo glasses to view. Abbreviations as before.

flat-bed scanner. Flat-bed scanners provide an extremely even illumination and are also able to produce high-resolution images (as documented in Haas et al., 2003). Further advantages of the use of a flat-bed scanner are that such a machine is easily available. This method is also extremely fast compared to a set up with a repro stand and lights. It is also possible for museum material, especially when borrowing is impossible, such as in the case of the holotype from the collection in Paris (MNHN R. 62691). In this way, specimens can be documented and comparable to similarly processed material, while it is much more complicated to replicate a definite setting for macrophotography.

Yet, even modern-day flat-bed scanners do not resolve high enough for objects, which are very far away from the glass surface. We, therefore, had to document one of the specimens (GSI M-8113) in a more classical way, i.e., using macrophotography. We applied cross-polarized light filters (Bengtson, 2000) as the surrounding matrix was simply too uneven and thus placed the fossil specimen too far from the scanning surface to obtain a satisfactory image.

Directed lighting is usually used to enhance the contrast of certain structures. Unfortunately, this is one reason why this type of lighting can cause artefacts, emphasizing certain structures while diminishing others. Nevertheless, contrast enhancement is very important for the investigated fossils of $U$. yehoachi due to the irregular colour pattern of the surface. Such an irregular pattern is found on the new specimen SMNS 67703, where it is especially caused by the dark dendrites (Figure 1). One possible solution for the suppression of such colour patterns is the use of ammonium-chloride (see Stein, 2010 for fossils from the Cambrian Sirius Passet, or Hegna, 2010 for extant specimens). But specimens treated in this way provide only one type of contrast, the relief, and are therefore best documented with directed light (which we wanted to avoid, see above). As the new specimen was originally part of a private collection, we also 

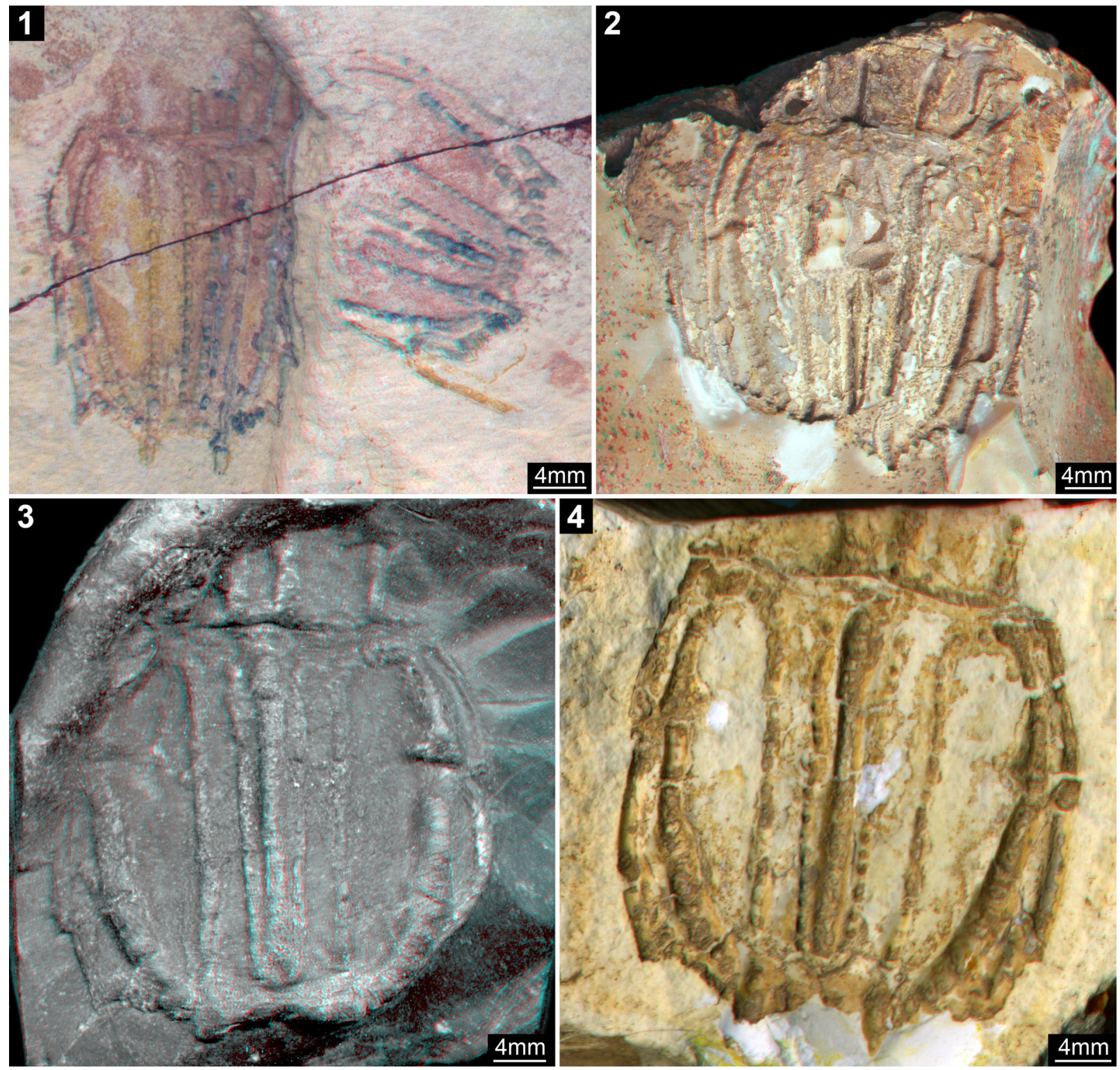

FIGURE 3. Red-cyan stereo images of all other known specimens of Ursquilla yehoachi (Remy and Avnimelech, 1955). 3.1, 3.2 and 3.4 are virtual peels, 3.3 is a normal stereo image. Use red-cyan stereo glasses to view. 3.1. Two specimens on one slab, BMNH I 7316, collections of the Natural History Museum London. 3.2. Specimen from the collections of the Geological Survey of Israel, Jerusalem, GSI M-8113. 3.3. Resin cast of the holotype (see Figure 3.4), BMNH I 15472, collections of the Natural History Museum London. 3.4. Holotype, MNHN R. 62691, from the collections of the Muséum national d'Histoire naturelle Paris.

did not want to apply a method directly affecting the surface of the fossil.

An alternative method successfully applied to other Mesozoic stomatopods is composite fluorescence microscopy. Fortunately, the new specimen of $U$. yehoachi autofluoresces also. With this method we could successfully document part of the telson (Figure 2.1), due to which we were able to clarify the status of the uropod as consisting of two elements (Figure 2.2; see below). Yet, the slab of the fossil was too thick in some areas and could simply not be placed under the microscope in a way to document it completely. This is a general difficulty with usual compound microscopes, which demands for better solutions in the future (for first attempts, see Haug, J.T. et al., 2011).

Another way of enhancing the contrast on a low-relief fossil is documenting its three-dimensional information. This has another important advantage: The fossil specimens of $U$. yehoachi 
are not simply imprints, apparent through the different fluorescent capacities of the fossil and the surrounding matrix, but provide the interior surface of the dorsal (cuticular) side of the animal (Hof, 1998a). In any case, it is difficult to understand the morphology of a once living animal based on a negative relief. Therefore, it is an advantage to be able to invert the relief virtually to a positive relief. Although the resulting surface is the inner surface and not the true outer surface, it is still closer to the latter one and easier to understand than the original negative relief provided by the actual fossil.

A classical method for physically inverting negative-relief fossils is to produce a cast or peel. This method has already been applied successfully by Hof (1998a) to the earlier known specimens of $U$. yehoachi. Casts can potentially damage specimens, and due to the rarity and uniqueness of the material we tried to find a method for 3D documentation that was "less physical."

Hörnschemeyer and Handschuh (2009) suggested the application of 3D surface scanning. This method could not be successfully applied to the original fossil, but only to a peel of it. Thus, this method, in the here described case, does not have the advantage of not directly interfering physically with the fossil. Also different structures are not as clear as with other methods. In the model of the micro-CT scan the structure of the uropodal exopod and the posterior tips of the telson become clearer than in the surface model of the surface scan of the peel (Figure 4.1-2). Conversely, the presence of carinae on the telson, including the elevated margin of the telson, is more apparent in the surface model of the surface scan of the peel (Figure 4.1-2). Also, in the surface model of the surface scan of the peel, pleomeres 5 and 6 appear more clearly as well as the tergopleurae of mainly the fifth pleomere (especially the left side; Figure 4.2).

Fortunately, a very simple method to invert the 3D topology of the fossils is to produce a stereo image with the flat-bed scanner. As the flat-bed scanner is easy to use and widely available, this was the perfect tool for documenting all specimens of $U$. yehoachi (Figures 1, 3.1, 3.3-4, 4.3; besides GSI M-8113 in Figure 3.2, see above; see also Figure 4.4 for an extant stomatopod). The term virtual peel, coined here for this procedure, emphasizes the fact that no physical interaction with the surface of the fossil is necessary, i.e., the risk of damaging rare fossils is minimized.

All available specimens of $U$. yehoachi are presented here as images from virtual peels (Fig- ures 1, 3.1-2, 3.4). An additional stereo image from flat-bed scanning of a cast of the holotype is presented for comparison (Figure 3.3). In all fossil specimens, delicate structures, such as tubercles or sharp carinae, are present and well visible with the virtual peel technique (see well-defined tubercles, e.g., in Figure 3.1; sharp carinae especially in Figure 3.2). The appearance of these structures in original specimens is very different from the cast of the holotype where such filigree structures are not evident. This becomes very apparent comparing the original holotype (Figure 3.4 ) with its cast (Figure 3.3): In the holotype, prominent tubercles on the accessory median and anterior submedian carinae visible lateral to the median carina, extending the length of the telson (Figure 3.4). They are not preserved in the cast (Figure 3.3). Furthermore, the terminal spines of the primary teeth of the telson, which are not well preserved in the holotype (compared to Figure 3.1-2), are completely lost in the cast (Figure 3.3).

The cast preserves structures less distinctively than they are in an original specimen. This is different in the virtual peel, where structures appear as filigree as they are in the original specimen. This is, of course, due to the lack of use of any casting compound, which can flatten structures or can disperse their true margins unless the compound is able to penetrate all aspects of the surface sculpture of the fossil. As in a virtual peel only the images are switched, the sharpness of the image does not suffer from any negative qualities of a casting compound and is only limited by the properties of the flat-bed scanner and its depth of field. Additionally, the virtual peel technique is superior to the physical peel method in both quality of the result and effort of achievement (see Figure $4.1,4.3)$.

In summary, it can be stated that flat-bed scanners are an ideal tool for documenting lowrelief fossils of a certain size (to our experience with A4 scanners scanned objects should not be larger than $20 \mathrm{~cm}$ in length and $15 \mathrm{~cm}$ in width to obtain stereo images with a satisfactory depth impression in an adequate timeframe, which, however, depends on the scanning resolution). They provide an extremely even lighting, offer the opportunity to document the specimen with topological information and even allow inverting the depth impression without physically interfering with the surface of the fossil, acting as a virtual peel. Surface scanners and micro-CT scanners also yield potential for such approaches, but are currently too 

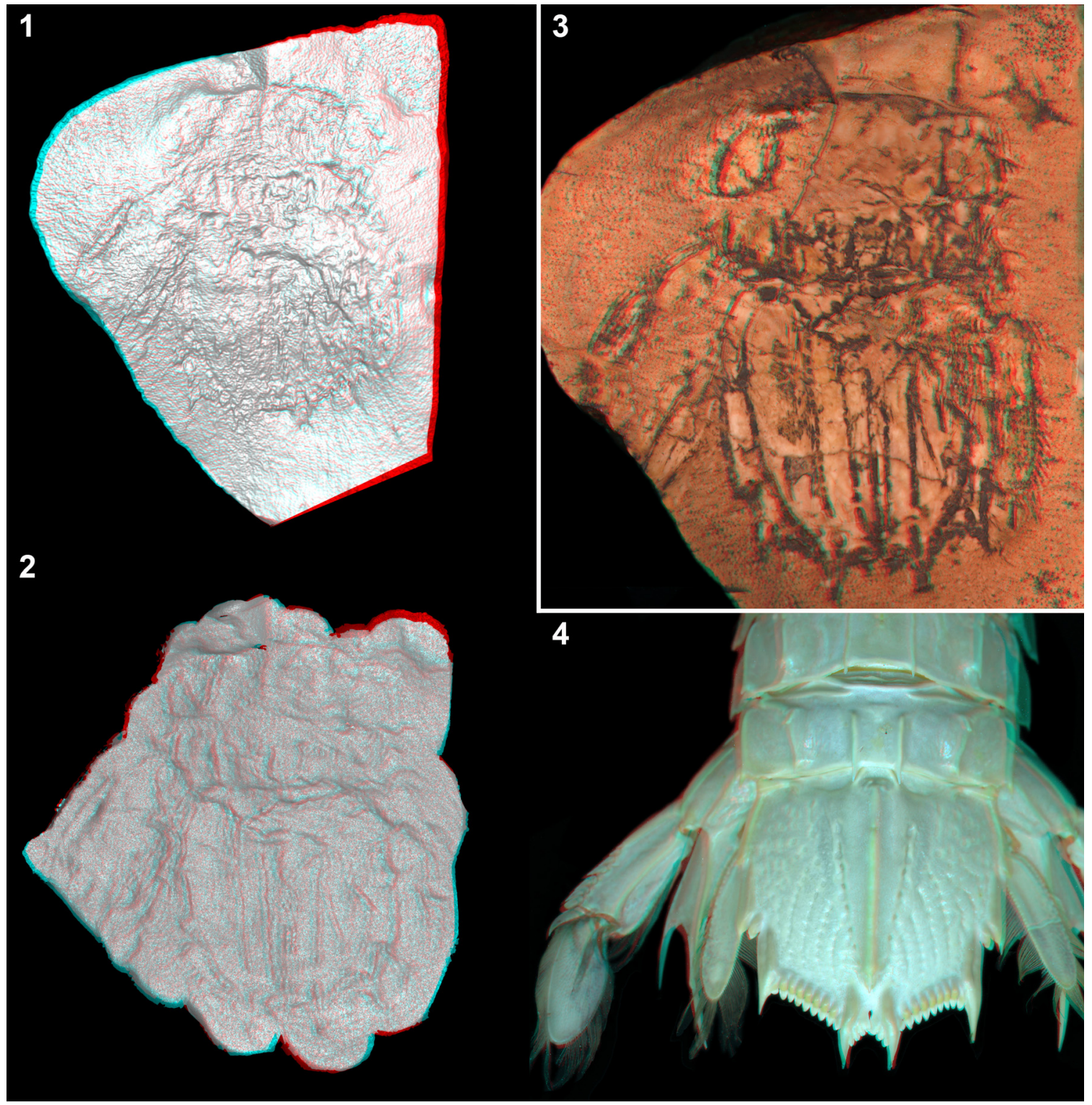

FIGURE 4. Method comparison and comparison with an extant specimen. All images are red-cyan stereo images, use red-cyan stereo glasses to view. 4.1-3. Specimen SMNS 67703 of Ursquilla yehoachi (Remy and Avnimelech, 1955). 4.1-2. Virtual surface models. 4.1. Surface model based on a micro-CT scan. 4.2. Surface model based on a surface scan of a peel out of dental casting compound of the fossil. 4.3. Virtual peel (same as Figure 1) for comparison. 4.4. The posterior region of an air-dried specimen of Squilla mantis (Linnaeus, 1758) for comparison, processed as the specimen in Figure 3.3, i.e., without depth inversion (normal stereo image). Images not to scale.

rarely available to become a standard method providing high comparability.

\section{Morphological and Systematic Interpretations}

The new specimen amends our knowledge of the morphology of Ursquilla yehoachi (Figure 5) in several significant aspects. These details will be discussed in the following, also concerning their possible implications for the systematic position of U. yehoachi.
Uropods. While the telson of $U$. yehoachi is well known from the earlier described specimens, the exact morphology of the uropods remained in part speculative. The uropods are of special interest for understanding the evolutionary history of Stomatopoda during the late Mesozoic period. Representatives of Verunipeltata have a uropodal exopod that is sub-divided into a proximal part usually carrying several movable "teeth" (spines) along 


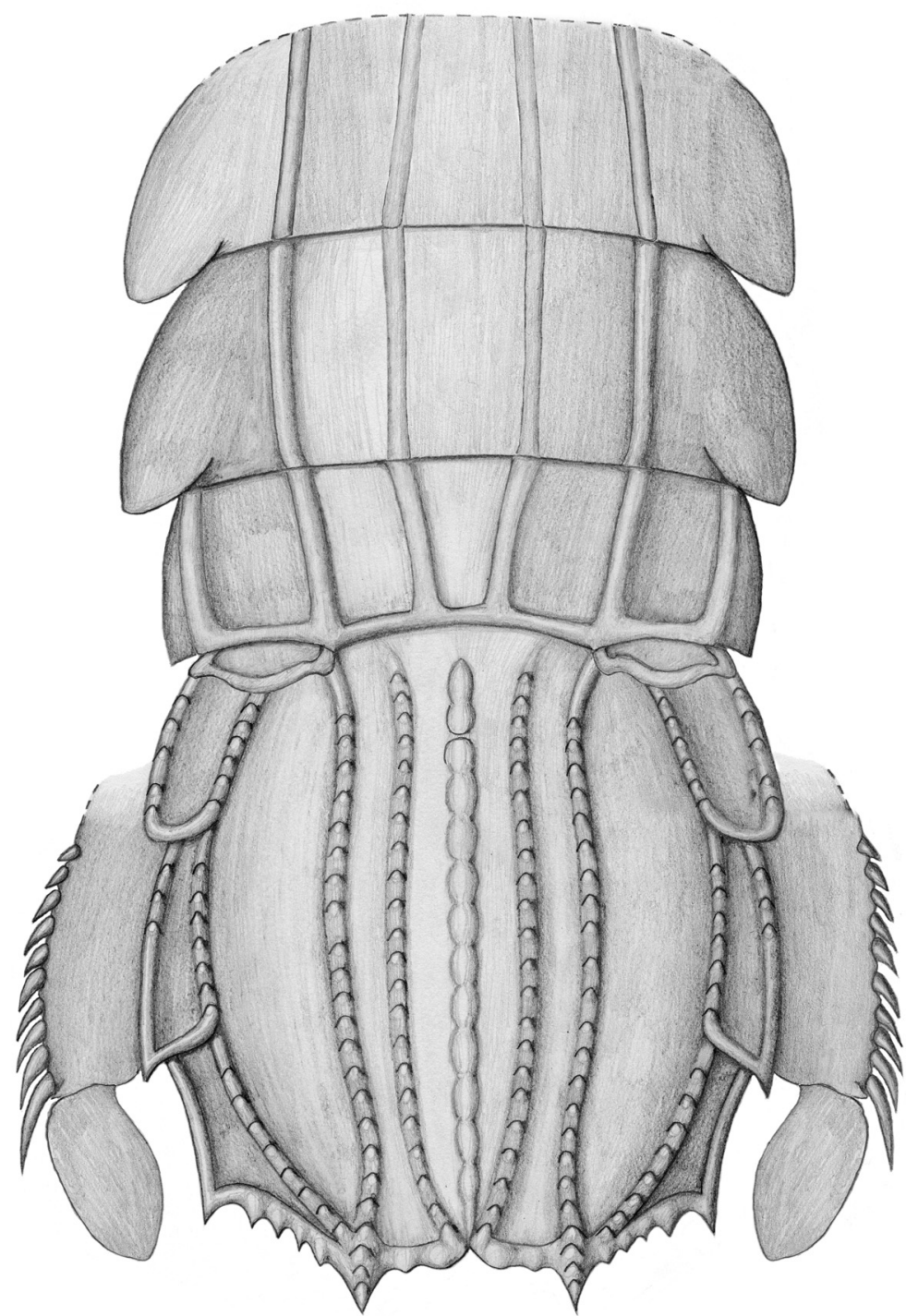

FIGURE 5. Tentative reconstruction of Ursquilla yehoachi (Remy and Avnimelech, 1955), represented as a scientific pencil drawing.

its lateral margin and a distal paddle bearing setae around its margin.

Representatives of Stomatopoda that branch off from the evolutionary lineage towards Verunipeltata have an undivided uropod exopod. In representatives of Unipeltata sensu lato, e.g., species of Sculda or Pseudosculda, the uropod exopod is armed with movable spines, as also in extant mantis shrimps, but these spines run right to the tip, there is no distal paddle-shaped element in these taxa (see, e.g., Haug, J.T. et al., 2010, their figure $6 \mathrm{~A})$.

Having this as a background, the find of a specimen of $U$. yehoachi with a preserved uropod was quite important (Hof, 1998a). Although Hof recognized $U$. yehoachi, based on the telson mor- phology, as a representative of Squilloidea, he interpreted the uropod as possibly being undivided. This could have either pointed to an exclusion of $U$. yehoachi not only from Squilloidea but also from Verunipeltata, or to an independent evolution of the divided uropod within Verunipeltata, or to an unusual apomorphic condition in $U$. yehoachi.

Our finding supports Hof's original interpretation of an in-group squilloid position of $U$. yehoachi, and more specifically, as in-group representative of Squillidae as was concluded by Ahyong (2005). Indeed, U. yehoachi possesses several characters of the verunipeltatan in-group Squillidae, such as prelateral lobes, submedian teeth with fixed apices and the general telson outline, which is subquadrate. Thus, Ursquillidae Hof, 1998, proposed by 


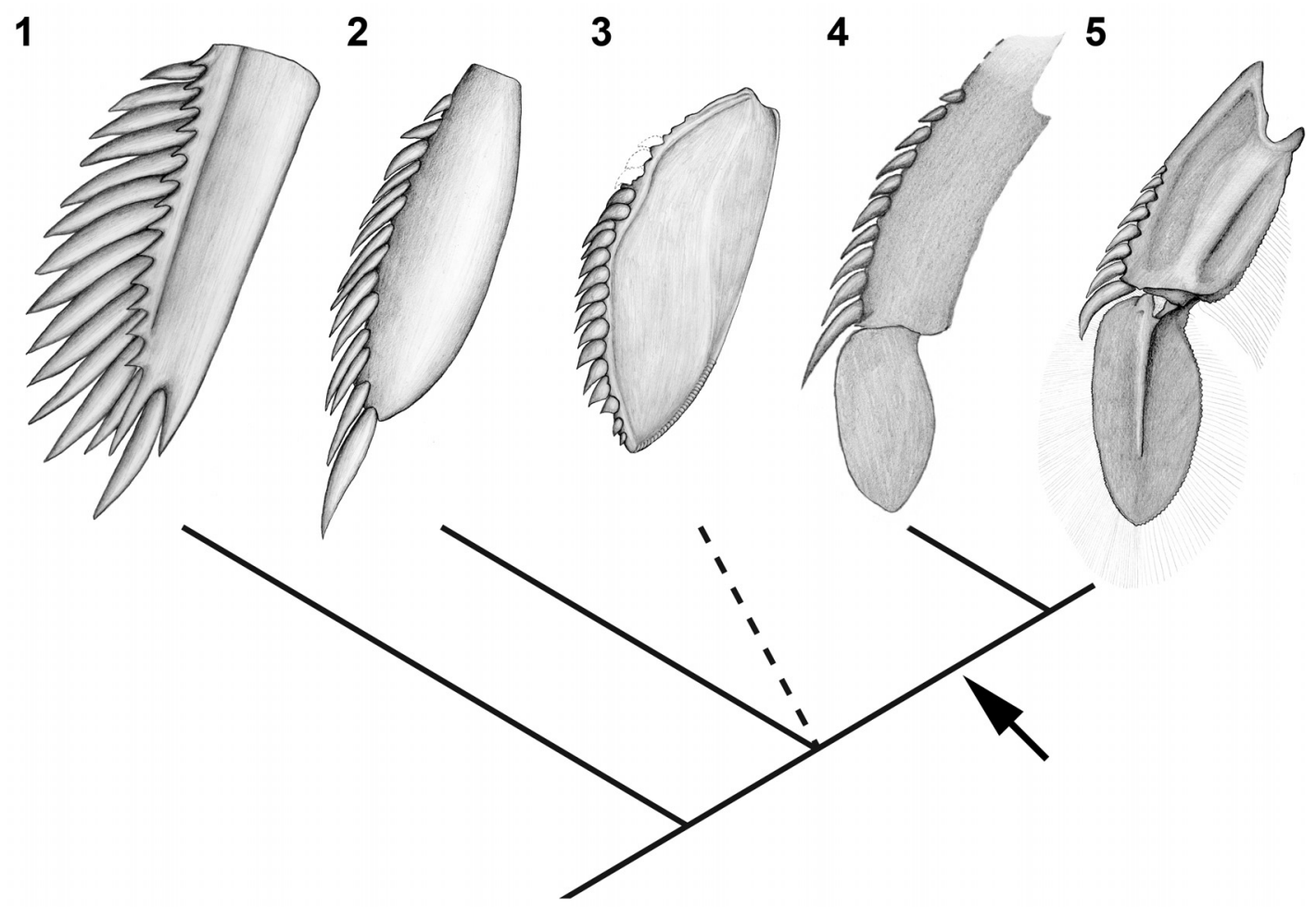

FIGURE 6. Uropod exopods of different Mesozoic and extant stomatopods and their phylogenetic positions within Unipeltata s. I. Arrow marks the occurrence of a bipartite uropodal exopod. 6.1. Sculda pennata Münster, 1840. 6.2. Pseudosculda laevis (Schlüter, 1874). 6.3. Supposed pseudosculdid from the Cretaceous of Mexico (Vega et al., 2007). 6.4. The herein re-evaluated Ursquilla yehoachi (Remy and Avnimelech, 1955); reconstruction, based on the new data. 6.5. Squilla mantis (Linnaeus, 1758). See Haug, J.T. et al. (2010) for details on relationships within Stomatopoda.

Hof (1998a) for Ursquilla, should be considered a junior synonym of Squillidae, as suggested by Ahyong $(2005,2012)$.

The presence of a modern type of uropod with a bipartite exopod in $U$. yehoachi demonstrates that this morphology was already present in the late Mesozoic. Such a bipartite uropodal exopod was also assumed for the Cretaceous gonodactyloid stomatopod Paleosquilla brevicoxa Schram, 1968, although not figured by a photograph (Schram, 1968). Other Mesozoic stomatopods that branched off from the evolutionary lineage toward Verunipeltata, such as Sculda pennata, Pseudosculda laevis or Archaeosculda phoenicia Ahyong, Garassino and Gironi, 2007 all have an undivided, elongate uropodal exopod (Figure 6.12; Ahyong et al., 2007). For future investigations a possible pseudosculdid, representing a yet unnamed species from the Cretaceous of Mexico, may prove to be of further significance for this issue (Vega et al., 2007). In this species the uropodal exopod appears to be "still" undivided, but its shape is more ovate than the slender exopods of S. pennata and P. laevis (Figure 6.3). In its ovate shape the exopod of the unnamed species resembles partly the shape of the uropodal exopods of many verunipeltatans (Figure 6.4-5), therefore could turn out to be more closely related to Verunipeltata than to $P$. laevis. A detailed re-investigation of this material is envisaged.

A prominent feature of the uropods of modern mantis shrimps is a large basipodal spine. Such spines are also known from representatives of stomatopods that branched off the lineage towards Verunipeltata, e.g., Pseudosculda laevis (Ahyong et al., 2007, their figure 4B) and Sculda pennata (Haug, J.T. et al., 2010, their figure 6A). Hence, $U$. yehoachi should have possessed such a structure, and it may be preserved on the left uropod of the new specimen, but without any visible details. Future finds of this rare fossil are expected to potentially preserve this structure more clearly.

Ontogenetic changes of the telson. The differences of the specimens of $U$. yehoachi in shape 
1

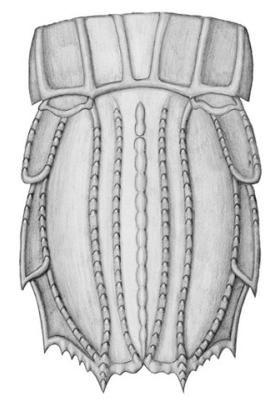

2

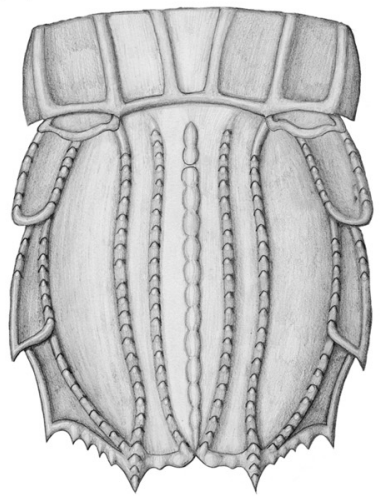

3

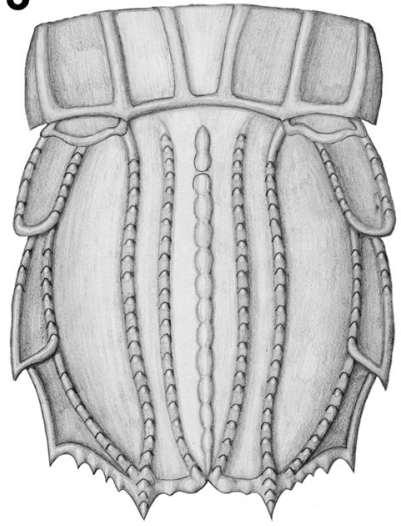

4

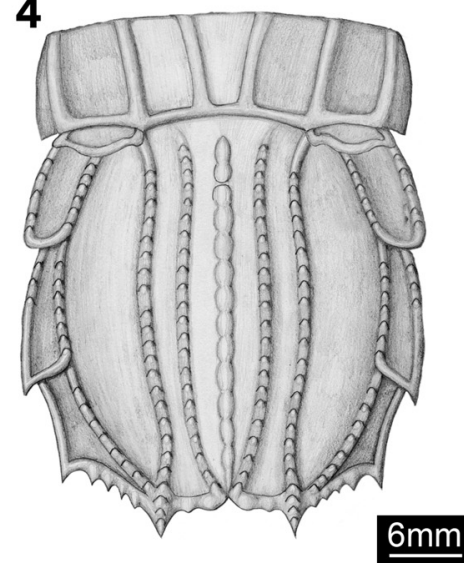

FIGURE 7. Size comparison of the known specimens of Ursquilla yehoachi (Remy and Avnimelech, 1955). To compare the length-to-width ratios, the reconstruction of the new specimen (SMNS 67703) was deformed according to the measured sizes of each of the other specimens. Lengths and widths given according to the illustrated part. 7.1. BMNH I 7316 (both specimens on this slab are of the same size; length: $3.1 \mathrm{~cm}$, width: $1.9 \mathrm{~cm}$, ratio: 1.6). 7.2. SMNS 67703 (length: $4.0 \mathrm{~cm}$, width: $3.0 \mathrm{~cm}$, ratio: 1.3). 7.3. GSI M-8113 (length: $4.2 \mathrm{~cm}$, width: $3.2 \mathrm{~cm}$, ratio: 1.3 ). 7.4 . MNHN R. 62691 (Holotype) (length: $4.4 \mathrm{~cm}$, width: $3.3 \mathrm{~cm}$, ratio: 1.3).

and size are interpreted by us as ontogenetic variation. The two smallest specimens (BMNH I 7316; both of the same size) are slenderer than the other specimens (Figure 7.1). As these two specimens lie on the same slab and close together, but oriented in different directions (Figure 3.1), this slender appearance cannot be explained by tectonic deformation. Two specimens (SMNS 67703, GSI $\mathrm{M}-8113)$ are more or less the same size and shape (Figure 7.2-3). The holotype of the species (MNHN R. 62691) is the largest of the whole series and also the broadest proportionally (Figure 7.4). Therefore, allometric growth of the telson, becoming relatively broader during ontogeny, is the most plausible explanation of the morphological variation within the material of $U$. yehoachi and is consistent with typical allometric change that occurs in modern stomatopods. Additionally, as with modern stomatopods, especially squilloids, the telson carinae in U. yehoachi become proportionally more inflated with increasing size. For the Mesozoic species Sculda pennata rather drastic changes of the morphology during juvenile development were reported (Haug, J.T. et al., 2010), but possible ontogenetic variation of the morphometry of the telson has not yet been studied.

Alternatively, one might interpret the observed differences as sexual dimorphism. If doing so, the smaller specimens would be interpreted as representing one sex, while the larger ones represent the other one. Yet, already among the larger specimens an allometric growth can be observed.
Therefore, an ontogenetic interpretation explains the observed pattern without further assumptions, while an interpretation as (sexual) dimorphs demands for additional explanations. Furthermore, ratio differences of the telson have to our knowledge not been reported between conspecific males and females of extant representatives.

\section{CONCLUSIONS AND OUTLOOK}

The results of our re-investigation of the available material of the Cretaceaous stomatopod Ursquilla yehoachi support previous assumptions on the phylogenetic position of $U$. yehoachi. Confirmation of a bipartite uropodal exopod on the new specimen (SMNS 67703) corroborates its in-group position within Verunipeltata, further characters (see above) even support a position of $U$. yehoachi within Squillidae, and accordingly the species is deeply nested within Stomatopoda. The apparent morphological variation within the material of $U$. yehoachi is interpreted as ontogenetic variation, i.e., the available specimens represent different stages within the ontogenetic sequence of the species. The ontogeny of $U$. yehoachi includes allometric growth of the telson.

For further conclusions on reconstructing the evolution of the stomatopod uropods also other fossil stomatopod species need to be re-studied, for example, the supposed pseudosculdid from the Cretaceous of Mexico (Vega et al., 2007) and Paleosquilla brevicoxa from the Cretaceous of Colombia (Schram, 1968). Already, the present 
example demonstrates that a single fossil can provide deeper insights into the evolution of mantis shrimps. This is not least due to the application of the new method named the virtual peel technique. This is a fast and easy to apply method for the documentation of low-relief fossils, especially for fossils preserved as a negative relief.

\section{ACKNOWLEDGEMENTS}

We thank S. Natkaniec, Düsseldorf, who found the new specimen and made it available for this study. G. Schweigert, Staatliches Museum für Naturkunde Stuttgart, identified the new specimen as a representative of Ursquilla yehoachi and kindly informed us about its existence and handed it over to us for this study. We are also grateful to D. Berman, Düsseldorf, who facilitated the loan of the specimen before it became part of the collection in Stuttgart. The investigation of the specimens with various methods was made possible through the help of $\mathrm{H}$. Rudolph, University of Ulm (surface scanning), the company Descam, Oberhaching, R. Jaumann and colleagues from the company Wenzel Knotenpunkt, Balingen (micro-CT), and $\mathrm{S}$. Liebau, University of UIm (fluorescence microscopy), for which we want to express our sincere thanks. Furthermore, Z. Lewy, Jerusalem, kindly organized the loan of the specimen from the collection of the Geological Survey of Israel. We also want to thank the curator $S$. Charbonnier of the crustacean collection of the Muséum national d'Histoire naturelle in Paris, who performed the scans of the holotype from the collections for us. $L$. Davis and G. Edgecombe from the Natural History Museum, London, kindly helped us to scan the specimens there. We furthermore thank all people involved in providing free software that was used during our studies such as CombineZM, Gimp, Inkscape, OpenOffice and Blender. JTH was kindly funded by the German Research Foundation (DFG) under Wa754/15-1 and by Yale University and the $A$. von Humboldt-Foundation $(\mathrm{AvH})$ with a Feodor Lynen fellowship for postdoctoral researchers and a Feodor Lynen return fellowship. $\mathrm{CH}$ was funded by the German Academic Exchange Service (DAAD) with a return fellowship. JTH and $\mathrm{CH}$ would like to thank their hosts D.E.G. Briggs, Yale University and the Yale Peabody Museum of Natural History, New Haven, and S. Harzsch, University of Greifswald, for their support. H. Porras (Museo de Múzquiz, Coahuila) facilitated loan of one specimen.

\section{REFERENCES}

Ahyong, S.T. 2005. Phylogenetic analysis of the Squilloidea (Crustacea: Stomatopoda). Invertebrate Systematics, 19:189-208.

Ahyong, S.T. 2012. The marine fauna of New Zealand: Mantis Shrimps (Crustacea: Stomatopoda). NIWA Biodiversity Memoir, 125:1-111.

Ahyong, S.T. and Harling, C. 2000. The phylogeny of the stomatopod Crustacea. Australian Journal of Zoology, 48:607-642.

Ahyong, S.T., Chan, T.-Y., and Liao, Y.-C. 2008. A Catalog of the Mantis Shrimps (Stomatopoda) of Taiwan. National Taiwan Ocean University, Keelung.

Ahyong S.T., Garassino A., and Gironi B. 2007. Archaeosculda phoenicia n. gen., n. sp. (Crustacea, Stomatopoda, Pseudosculdidae) from the Upper Cretaceous (Cenomanian) of Lebanon. Atti della Società italiana di Scienze naturali e del Museo civico di Storia naturale in Milano, 148(I):3-15.

Bengtson, S. 2000. Teasing fossils out of shales with cameras and computers. Palaeontologia Electronica, $3(1)$, art. 4:14pp.

Calman,W.T. 1904. On the classification of the Crustacea Malacostraca. Journal of Natural History, Series 7, 13:144-158.

De Angeli, A. and Garassino, G. 2008. Pseudosquilla lessinea n. sp. (Crustacea, Stomatopoda, Pseudosquillidae) and Scyllarides bolcensisi n. sp. (Crustacea, decapoda, Scyllaridae) from the lower Eocence (Ypresian) of Monte Postale (Altissimo, Vincenza, NE Italy). Atti della Società italiana di Scienze naturali e del Museo civico di Storia naturale in Milano, 149(II):167-178

Glaessner, M.F. 1969. Decapoda, p. R399-R533. In Moore, R.C. and Teichert C. (eds.), Treatise on Invertebrate Paleontology, Part R, Arthropoda 4. Geological Society of America, University of Kansas Press, Lawrence.

Haas, F., Waloszek, D., and Hartenberger, R. 2003. Devonohexapodus bocksbergensis, a new marine hexapod from the Lower Devonian Hunsrück Slates, and the origin of Atelocerata and Hexapoda. Organisms Diversity and Evolution, 3:39-54.

Haug, J.T., Haug, C., and Ehrlich, M. 2008. First fossil stomatopod larva (Arthropoda: Crustacea) and a new way of documenting Solnhofen fossils (Upper Jurassic, Southern Germany). Palaeodiversity, 1:103-109.

Haug, C., Haug, J.T., and Waloszek, D. 2009a. Morphology and ontogeny of the Upper Jurassic mantis shrimp Spinosculda ehrlichi n. gen. n. sp. from southern Germany. Palaeodiversity, 2:111-118.

Haug, C., Haug, J.T., Waloszek, D., Maas, A., Frattigiani, R., and Liebau, S. 2009b. New methods to document fossils from lithographic limestones of southern Germany and Lebanon. Palaeontologia Electronica 12(3), 6T. 
Haug, J.T., Haug, C., Maas, A., Kutschera, V., and Waloszek, D. 2010. Evolution of mantis shrimps (Stomatopoda, Malacostraca) in the light of new Mesozoic fossils. BMC Evolutionary Biology, 10, art. 290:17 pp.

Haug, J.T., Haug, C., Kutschera, V., Mayer, G., Maas, A., Liebau, S., Castellani, C., Wolfram, U., Clarkson, E.N.K., and Waloszek, D. 2011. Autofluorescence imaging, an excellent tool for comparative morphology. Journal of Microscopy, 244:259-272.

Hegna, T.A. 2010. Photography of soft-bodied crustaceans via drying, whitening, and splicing. Journal of Crustacean Biology, 30:351-356.

Hörnschemeyer, T. and Handschuh, L. 2009. Untersuchung von Insektenfossilien mittels 3D-Laserscanning - Neue Möglichkeiten zur Merkmalsbeurteilung. Terra Nostra: Schriften der GeoUnion Alfred Wegener Stiftung, 2009/3:51.

Hof, C.H.J. 1998a. Late Cretaceous stomatopods (Crustacea: Malacostraca) from Israel and Jordan. Contributions to Zoology, 67(4):257-266.

Hof, C.H.J. 1998b. Fossil stomatopods (Crustacea: Malacostraca) and their phylogenetic impact. Journal of Natural History, 32:1567-1576.

Kerp, H. and Bomfleur, B. 2011. Photography of plant fossils-New techniques, old tricks. Review of Palaeobotany and Palynology, 166:117-151.

Latreille, P.A. 1802. Histoire naturelle, générale et particulière, des Crustacés et des Insectes 3. F. Dufart, Paris.

Latreille, P.A. 1816. Les crustacés, les arachnides et les insectes, 653 p. In Cuvier, G. (ed.), Le règne animal distribué d'après son organisation, pour servir de base à l'histoire naturelle des animaux et d'introduction à l'anatomie comparée. Vol. 3, Paris, Déterville.

Latreille, P.A. 1825. Familles naturelles du règne animal,exposées succinctement et dans un ordre analytique, avec l'indication de leurs genres. J.B. Baillière, Paris.

Linnaeus, C. 1758. Systema Naturae per Regna Tria Naturae, Secundum Classes, Ordines, Genera, Species, cum Characteribus, Differentiis, Synonymis Locis. Edition 10, vol.1. Holmiae.
Münster, G. Graf zu 1840. Ueber einige Isopoden in den Kalkschiefern von Bayern. Beiträge zur Petrefaktenkunde, 3:19-23.

Remy, J.-M. and Avnimelech, M. 1955. Eryon yehoachi nov. sp. et Cenomanocarcinus cf. vanstraeleni Stenzel Crustacés décapodes du Crétacé supérieur de l'état de l'Israël. Bulletin de la Société Géologique de France, 5:311-314.

Schlüter, C. 1874. Ueber einige jurassische CrustaceenTypen in der oberen Kreide I; Fossile Krebse des Libanon. Sitzungsberichte herausgegeben vom naturhistorischen Verein der Preussischen Rheinlande und Westfalens, 31:41-45.

Schram, F.R. 1968. Paleosquilla gen. nov.-a stomatopod (Crustacea) from the Cretaceous of Colombia. Journal of Paleontology, 42(5):1297-1301.

Schram, F.R. 2010. Catalog of the Fossil and Recent Stomatopoda. Unpublished update of Schram, F.R. and H.-G. Müller 2004. Catalog and Bibliography of the Fossil and Recent Stomatopoda. Backhuys Publishers, Leiden.

Schram, F.R. and Müller, H.-G. 2004. Catalog and Bibliography of the Fossil and Recent Stomatopoda. Backhuys Publ., Leiden.

Schubert, R. 2000. Using a flatbed scanner as a stereoscopic near-field camera. IEEE Computer Graphics and Application Issues, 20(2):38-45.

Schweitzer, C.E. and Feldmann, R.M. 2010. New fossil decapod crustaceans from the Remy Collection, Muséum national d'Histoire naturelle, Paris. Geodiversitas, 32:399-415.

Stein, M. 2010. A new arthropod from the Early Cambrian of North Greenland, with a 'great appendage'like antennula. Zoological Journal of the Linnean Society, 158:477-500.

Vega, F.J., Nyborg, T., Rojas-Briceño, A., Patarroyo, P., Luque, J., Porras-Múzquiz, H., and Stinnesbeck, W. 2007. Upper Cretaceous Crustacea from Mexico and Colombia: similar faunas and environments during Turonian times. Revista Mexicana de Ciencias Geológicas, 24:403-422.

Wetzel, W. 1973. Zwei altpaläozoische Geschiebe mit neuartigen problematischen Fossilien. Schriften des Naturwissenschaftlichen Vereins für Schleswig-Holstein, 43:44-45. 